\title{
GABA and Topiramate Inhibit the Formation of Human Macrophage-Derived Foam Cells by Modulating Cholesterol- Metabolism-Associated Molecules
}

\author{
Ying Yanga,b,c Yi-Tian Lian ${ }^{a, c}$ Shi-Yuan Huang ${ }^{a, c}$ Yong Yang ${ }^{a}$ Long-Xian Cheng $^{a}$ \\ Kun Liua
}

aDepartment of Cardiology, Union Hospital, Huazhong University of Science and Technology, Wuhan, China, ${ }^{b}$ Affiliated Hospital of North Sichuan Medical College, Nanchong, China; 'These authors contributed equally to this work

\section{Key Words}

Macrophage $\cdot$ Atherosclerosis $\cdot$ Cholesterol $\cdot$ GABA $\cdot$ GABA receptor agonist

\begin{abstract}
Aims: $y$-aminobutyric acid (GABA), the principal inhibitory neurotransmitter, acts on GABA receptors to play an important role in the modulation of macrophage functions. The present study examined the effects of GABA and a GABA receptor agonist on modulating cholesterolmetabolism-associated molecules in human monocyte-derived macrophages (HMDMs). Methods: ORO stain, HPLC, qRT-PCR, Western blot and EMSA were carried out using HMDMs exposed to ox-LDL with or without GABAergic agents as the experimental model. Results: GABA and topiramate reduced the percentage of cholesterol ester in lipid-laden HMDMs by down-regulating SR-A, CD36 and LOX-1 expression and up-regulating ABCA1, ABCG1 and SR-BI expression in lipid-laden HMDMs. The production of TNF- $\alpha$ was decreased in GABAand topiramate-treated lipid-laden HMDMs, and levels of interleukin (IL)- 6 did not change. The activation of two signaling pathways, p38MAPK and NF- $\kappa B$, was repressed by GABA and topiramate in lipid-laden HMDMs. Conclusion: GABA and topiramate inhibit the formation of human macrophage-derived foam cells and may be a possibility for macrophage targeted therapy of atherosclerotic lesions.
\end{abstract}




\section{Introduction}

Plaque macrophages are the key innate immune cells that are involved in the pathogenesis of atherosclerosis [1]. The best understood pathological process mediated by macrophages is their inability to properly process modified lipoproteins, resulting in the formation of foam cells, which is a dangerous component of atherosclerotic plaque [2]. Many molecules are involved in the recognition and processing of modified lipoproteins. Scavenger receptors, such as scavenger receptor class A (SR-A), lectin-like oxidized low-density lipoprotein receptor-1 (LOX-1) and CD36, mediate foam cell formation by facilitating the uptake of modified lipids [3, 4]. Acyl-CoA:cholesterol acyltransferase (ACAT) 1, ATP-binding cassette (ABC) A1, ABCG1 and scavenger receptor class B type I (SR-BI) affect macrophage cholesterol metabolism and transport [5-7]. It is clinically promising to modulate the expression of these cholesterol-metabolism-associated molecules in macrophages.

It is well established that there is an extensive cross-talk between the immune system and the nervous system. GABA, the principal inhibitory neurotransmitter, is one of the molecules participating in the exchange between the two systems [8]. Several recent studies have shown that immune cells, such as macrophages, dendritic cells and T cells, are capable of synthesizing GABA and expressing functional GABA receptors [9]. GABA acts on GABA receptors to affect a variety functional properties of the immune cells, such as cytokine secretion, cell proliferation, phagocytic activity and chemotaxis $[10,11]$. Increasing GABAergic activity ameliorates the progression of autoimmune diseases, such as multiple sclerosis, diabetes mellitus and rheumatoid arthritis [12-15].

In view of the immunoinhibitory role of the GABA-GABA receptor signaling system, we hypothesize that GABA and GABA receptor agonist, such as topiramate, a GABA-A receptor agonist and baclofen ,a GABA-B receptor agonist, exhibit inhibitory effects on phagocytic activity for cholesterol in HMDMs.

\section{Materials and Methods}

\section{Ethics statement}

Our experiment used fresh plasma and peripheral blood mononuclear cells from normolipidemic volunteers with their consent, and the study was approved by the Wuhan Blood Centre (authorizations: 2011-8) and conformed to Declaration of Helsinki.

LDL isolation and oxidization

Native LDLs (densities ranging from 1.006 to $1.063 \mathrm{~g} / \mathrm{ml}$ ) were isolated from fresh plasma of normolipidemic volunteers by sequential preparative ultracentrifugation according to published standard protocols [16]. LDLs were oxidized with $10 \mu \mathrm{M} \mathrm{CuCl}_{2}$ to obtain ox-LDL.

\section{Isolation of human PBMCS}

Human peripheral blood mononuclear cells (PBMCs) were isolated from peripheral blood samples of healthy volunteers by Ficoll density gradient centrifugation and grown in RPMI 1640 medium supplemented with $10 \%$ fetal bovine serum at $37^{\circ} \mathrm{C}$ in $5 \% \mathrm{CO}_{2}$ and $95 \%$ humidity for seven days to induce differentiation into HMDMs.

\section{Treatment of HMDMs with GABAergic agents}

After differentiation, HMDMs were exposed to $100 \mu \mathrm{g} / \mathrm{ml}$ ox-LDL in the presence of GABA (Sigma, Saint Louis, US) at concentrations of $0.1,1$ or $1000 \mu \mathrm{M}$ for $1 \mathrm{~h}$; GABA-A receptor agonist topiramate (Sigma, Saint Louis, US) at concentrations of 2, 20 or $200 \mu \mathrm{M}$ for $1 \mathrm{~h}$; or GABA-B receptor agonist baclofen (Sigma, Saint Louis, US) at concentrations of 1,10 or $100 \mathrm{nM}$ for $1 \mathrm{~h}$. HMDMs treated with GABA, topiramate or baclofen were exposed to $100 \mu \mathrm{g} / \mathrm{ml}$ ox-LDL for $48 \mathrm{~h}$ to accelerate foam cell formation with less toxicity or apoptosis. Meanwhile, to further observe the action of GABA, topiramate or baclofen, HMDMs were exposed to $100 \mu \mathrm{g} / \mathrm{ml}$ ox-LDL for 24 or $36 \mathrm{~h}$ in the presence of $1 \mu \mathrm{M}$ GABA, $20 \mu \mathrm{M}$ topiramate or $10 \mathrm{nM}$ baclofen. HMDMs exposed to GABA, topiramate, baclofen or $100 \mu \mathrm{g} / \mathrm{ml}$ ox-LDL were cultured for $48 \mathrm{~h}$. 
Table 1. Primer sequences used for Real-time quantitative reverse transcriptase polymerase chain reaction

\begin{tabular}{|c|c|}
\hline Molecules & Sequence \\
\hline \multirow[t]{2}{*}{ SR-A } & Forward 5'-GCAGTTCTCATCCCTCTCAT-3' \\
\hline & Reverse 5'-GGTATTCTCTTGGATTTTGCC-3' \\
\hline \multirow[t]{2}{*}{$\operatorname{CD} 36$} & Forward 5'-TGCCTCTCCAGTTGAAAACCC- $3^{\prime}$ \\
\hline & Reverse 5'-GCAACAAACATCACCACACCA-3' \\
\hline \multirow[t]{2}{*}{ LOX-1 } & Forward 5'-CGGCAACAAGCAGAAGAAGC- $3^{\prime}$ \\
\hline & Reverse 5'-TGAGCCCGAGGAAAATAGGTAA-3' \\
\hline \multirow[t]{2}{*}{ ACAT1 } & Forward 5'-TGGGCAATGGAGTCTTACTCTGCT-3' \\
\hline & Reverse 5'-AAACAGCTGGCTCCAAATCAGGGA-3' \\
\hline \multirow[t]{2}{*}{ ABCA1 } & Forward 5'-TACAGCCAGAAAGACACCAG-3' \\
\hline & Reverse 5'-CACAGTAGACTTTGGGAGAG-3' \\
\hline \multirow[t]{2}{*}{ ABCG1 } & Forward 5'-CAGGAAGATTAGACACTGTGG-3' \\
\hline & Reverse 5'-GAAAGGGGAATGGAGAGAAGA-3' \\
\hline \multirow[t]{2}{*}{ SR-B I } & Forward 5'-AACAACTCCGACTCTGGGCTCT-3' \\
\hline & Reverse 5'-CATTTGCCCAGAAGTTCCATTG-3' \\
\hline \multirow[t]{2}{*}{ GAPDH } & Forward 5'-ATGGTGGTGAAGACGCCAGTA-3' \\
\hline & Reverse 5'-GGCACAGTCAAGGCTGAG AATG-3' \\
\hline
\end{tabular}

\section{Cholesterol content analysis}

Cells were counterstained with oil red O (ORO) and hematoxylin following the routine procedure. Cells with a lipid droplet area no less than the width of the nucleus were designated ORO positive (ORO+). The ORO+ cells were counted [17].

High performance liquid chromatography (HPLC) was conducted as follows. Briefly, cells were sonicated and lysed before triglycerides and proteins were eliminated from cell lysates. Lysates were then dissolved in a solution of $n$-hexane and isopropanol (4:1, V/V), and free cholesterol (FC) was extracted. One aliquot sample was treated with cholesterol esterase to obtain total cholesterol (TC) content. Samples were dried through a vacuum degasser and dissolved in a mobile phase containing isopropanol: $\mathrm{n}$-heptane: acetonitrile (35:12:52, V/V). TC and FC were measured by a chromatography system (VARIAN Prostar 210). Cholesterol ester (CE) was calculated through the subtraction of FC from TC.

\section{Assessment of mRNA}

Total RNA was extracted from HMDMs using TRIzol reagent (Invitrogen, Carlsbad, CA). Quantitative Real Time PCR (qRT-PCR) was performed using One Step SYBR PrimeScript RT-PCR Kit (Takara, Dalian, CN) and ABI PRISM 7500 Sequence system (Applied Biosystems) according to the manufacturers' protocols. Glyceraldehyde-3-phosphate dehydrogenase (GAPDH) was used as an endogenous control. Fold changes in mRNA expression level normalized to GAPDH were calculated by the comparative Ct method formula $2^{-\Delta \Delta C t}$. PCR primers are shown in Table 1.

\section{Western blotting analysis}

Total protein extracts were prepared and then subjected to Western blotting analysis. After SDSpolyacrylamide gel electrophoresis, proteins were transferred onto nitrocellulose membranes and detected by the corresponding primary antibodies against SR-A (Santa Cruz Biotechnology, Santa Cruz, CA), LOX-1 (R\&D, Minneapolis, MN), ACAT1 (Cayman, Ann Arbor, MI), ABCA1 (Abcam, London, UK), ABCG1 (Epitomics, Burlingame, CA), SR-BI (Epitomics, Burlingame, CA), p-p38MAPK/p38MAPK (CST, Boston, US), pAKT/AKT (CST, Boston, US) and GAPDH (Beyotime, Haimen, CN), and the following horseradish peroxidase (HRP)conjugated secondary antibodies. The proteins were visualized with the Enhance Chemiluminescence kit (ECL, Thermo, Rockford, IL). Semiquantitative analysis of films was performed with the Image-Pro Plus analysis software.

\section{ELISA assays of cytokines production}

Levels of TNF- $\alpha$ and IL-6, which accumulated in the cell culture supernatant, were measured by using a commercial ELISA kit according to the manufacturer's instructions (eBioscience, San Diego, CA).

Electrophoretic mobility shift assays (EMSA)

Five micrograms of nuclear extracts was prepared, and non-radioactive EMSA was performed using an EMSA kit according to the manufacturer's instructions (Pierce, Rockford, US) as described previously. Briefly, nuclear protein extracts were incubated with the double-stranded NF- $\kappa B$ consensus oligonucleoti- 
Fig. 1. Effects of GABAergic agents on cellular cholesterol content in HMDMs exposed to $100 \mu \mathrm{g} / \mathrm{ml}$ ox-LDL. Intracellular lipid droplets were observed by ORO staining. Lipid droplets were stained red and nuclei blue (A-C) and ORO+ cells were counted (D-F). A-1, B-1 and C-1, HMDMs were cultured for $48 \mathrm{~h}$. A-2, HMDMs exposed to $1 \mu \mathrm{M}$ GABA alone were cultured for 48 h. A-3, B-3 and C-3, HMDMs exposed to $100 \mu \mathrm{g} / \mathrm{ml}$ ox-LDL alone were cultured for $48 \mathrm{~h}$. A-4, HMDMs exposed to $100 \mu \mathrm{g} /$ $\mathrm{ml}$ ox-LDL in the presence of 1 $\mu \mathrm{M}$ GABA were cultured for $48 \mathrm{~h}$. B-2, HMDMs exposed to $20 \mu \mathrm{M}$ topiramate alone were cultured for 48 h. B-4, HMDMs exposed to $100 \mu \mathrm{g} / \mathrm{ml}$ ox-LDL in the presence of $20 \mu \mathrm{M}$ topiramate were cultured for 48 h. C-2, HMDMs exposed to $10 \mathrm{nM}$ baclofen alone were cultured for $48 \mathrm{~h}$. C-4, HMDMs exposed to $100 \mu \mathrm{g} / \mathrm{ml}$ ox-LDL in the presence of $10 \mathrm{nM}$ baclofen were cultured for $48 \mathrm{~h}$. $\mathrm{D}-\mathrm{F}$, The number of ORO+ cells in each group $(\mathrm{n}=3)$. ${ }^{*} P<0.05$ versus blank group (HMDMs were cultured for $48 \mathrm{~h}$ ); $P<0.05$ versus HMDMs exposed to $100 \mu \mathrm{g} /$ ml ox-LDL alone.

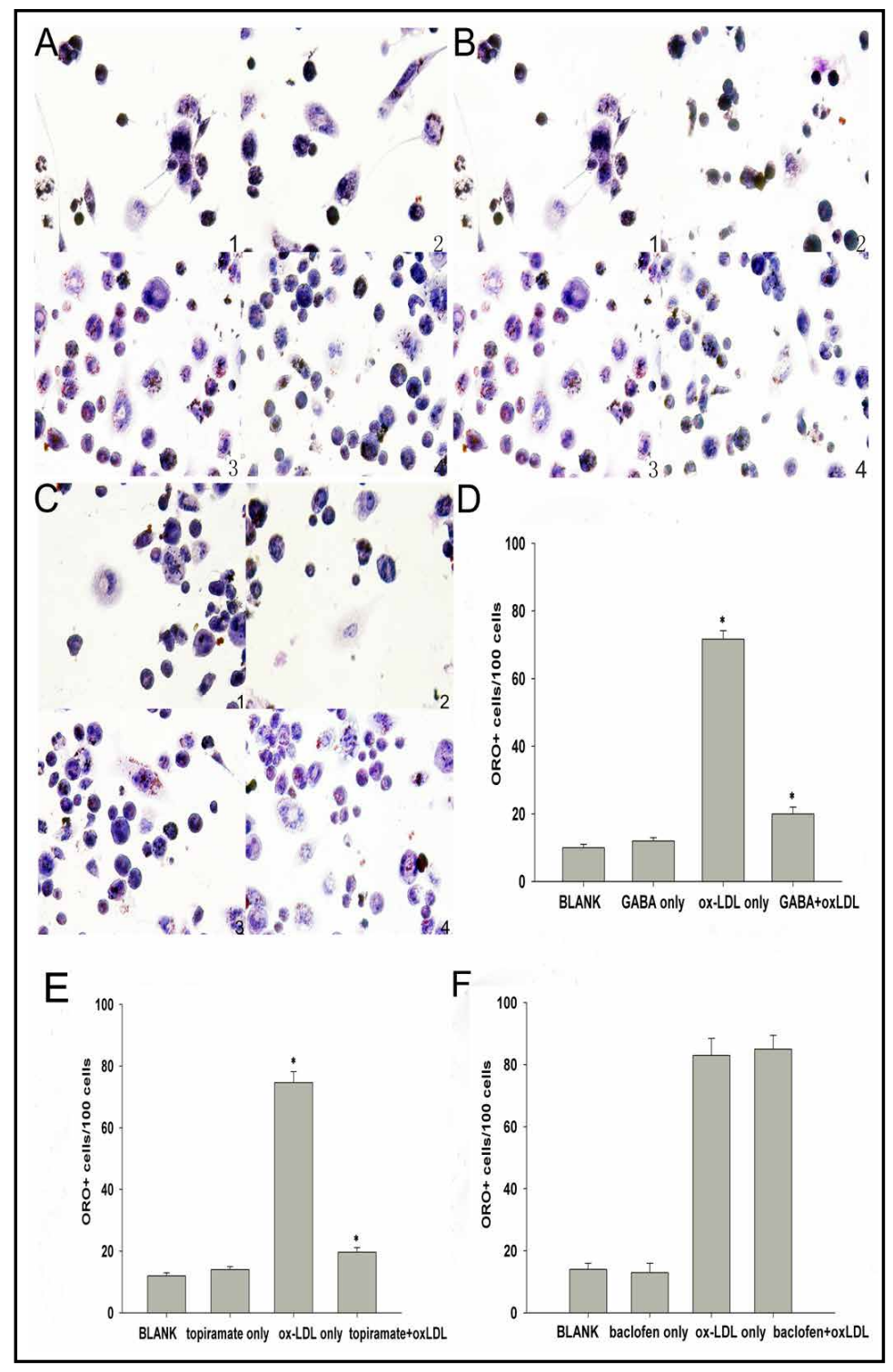

de (5'-AGTTGAGGGACTTTCCCAGGC-3') [18, 19], which was end-labeled with biotin-11-UTP using Biotin 3' End DNA Labeling Kit according to the manufacturer's instructions (Pierce, Rockford, US).

\section{Statistical analysis}

Data were expressed as the mean \pm SEM. SPSS 11.0 software was used for statistical analysis. Comparison of mean values between groups was evaluated by one-way, multirange ANOVA for multiple comparisons. $P<0.05$ was considered significant.

\section{Results}

GABA and topiramate reduce cholesterol content in HMDMs exposed to ox-LDL and enhance apoA-I-mediated cholesterol efflux

We directly quantified cholesterol content in HMDMs exposed to $100 \mu \mathrm{g} / \mathrm{ml}$ ox-LDL in the presence or absence of GABA, topiramate or baclofen by ORO staining. When HMDMs were exposed to $100 \mu \mathrm{g} / \mathrm{ml}$ ox-LDL, lipid droplets increased (Fig. $1 \mathrm{~A}-3$, B-3 and C-3). In the 
Table 2. Effect of GABA on TC, FC and CE in HMDMs exposed to $100 \mu \mathrm{g} / \mathrm{ml}$ ox-LDL. Data represent the mean \pm SEM $(\mathrm{n}=3) .{ }^{*} P<0.05$ versus HMDMs exposed to $100 \mu \mathrm{g} / \mathrm{ml}$ ox-LDL alone

\begin{tabular}{lcccccccc}
\hline GABA $(\mu \mathrm{M})$ & 0 & 1 & 0 & 0.1 & 1 & 1 & 1 & 1000 \\
$\begin{array}{l}\text { Exposure time } \\
\text { in ox-LDL (h) }\end{array}$ & - & - & 48 & 48 & 24 & 36 & 48 & 48 \\
\hline $\mathrm{TC}(\mathrm{mg} / \mathrm{dl})$ & $145.5 \pm 13.1$ & $142.5 \pm 10.3$ & $265.9 \pm 14.5$ & $243.9 \pm 9.2^{*}$ & $227.9 \pm 7.4^{*}$ & $218.3 \pm 10.2^{*}$ & $195.3 \pm 6.9^{*}$ & $198.7 \pm 6.5^{*}$ \\
$\mathrm{FC}(\mathrm{mg} / \mathrm{dl})$ & $93.4 \pm 3.2$ & $85.7 \pm 5.2$ & $94.1 \pm 7.9$ & $125.1 \pm 14.1^{*}$ & $127.1 \pm 6.6^{*}$ & $125.2 \pm 7.5^{*}$ & $112.2 \pm 11.5^{*}$ & $119.8 \pm 9.8^{*}$ \\
$\mathrm{CE}(\mathrm{mg} / \mathrm{dl})$ & $52.1 \pm 1.6$ & $56.7 \pm 5.0$ & $171.7 \pm 22.4$ & $118.4 \pm 23.3^{*}$ & $100.7 \pm 2.15^{*}$ & $93.1 \pm 3.3^{*}$ & $83.1 \pm 5.0^{*}$ & $78.8 \pm 7.2^{*}$ \\
\hline
\end{tabular}

Table 3. Effect of topiramate on TC, FC and CE in HMDMs exposed to $100 \mu \mathrm{g} / \mathrm{ml}$. Data represent the mean \pm SEM (n=3). ${ }^{*} P<0.05$ versus HMDMs exposed to $100 \mu \mathrm{g} / \mathrm{ml}$ ox-LDL alone

\begin{tabular}{lcccccccc}
\hline Topiramate $(\mu \mathrm{M})$ & 0 & 20 & 0 & 2 & 20 & 20 & 20 & 200 \\
$\begin{array}{l}\text { Exposure time in } \\
\text { ox-LDL }(\mathrm{h})\end{array}$ & - & - & 48 & 48 & 24 & 36 & 48 & 48 \\
& & & & & & & & \\
\hline TC $(\mathrm{mg} / \mathrm{dl})$ & $145.5 \pm 13.1$ & $137.2 \pm 6.9$ & $265.9 \pm 14.5$ & $218.2 \pm 7.6^{*}$ & $202.1 \pm 9.2^{*}$ & $185.0 \pm 7.8^{*}$ & $164.4 \pm 5.7^{*}$ & $152.5 \pm 5.8^{*}$ \\
$\mathrm{FC}(\mathrm{mg} / \mathrm{dl})$ & $93.4 \pm 3.2$ & $75.4 \pm 5.7$ & $94.1 \pm 7.9$ & $113.0 \pm 6.2^{*}$ & $108.4 \pm 7.9^{*}$ & $98.9 \pm 5.4^{*}$ & $98.7 \pm 5.0^{*}$ & $100.3 \pm 9.3^{*}$ \\
$\mathrm{CE}(\mathrm{mg} / \mathrm{dl})$ & $52.1 \pm 1.6$ & $61.7 \pm 12.6$ & $171.7 \pm 22.4$ & $105.1 \pm 13.7^{*}$ & $93.7 \pm 17.0^{*}$ & $86.2 \pm 3.5^{*}$ & $65.6 \pm 0.6^{*}$ & $52.2 \pm 11.0^{*}$
\end{tabular}

Table 4. Effect of baclofen on TC, FC and CE in HMDMs exposed to $100 \mu \mathrm{g} / \mathrm{ml}$ ox-LDL. Data represent the mean \pm SEM (n=3). ${ }^{*} P<0.05$ versus HMDMs exposed to $100 \mu \mathrm{g} / \mathrm{ml}$ ox-LDL alone

\begin{tabular}{lcccccccc}
\hline Baclofen (nM) & 0 & 10 & 0 & 1 & 10 & 10 & 10 & 100 \\
$\begin{array}{l}\text { Exposure time in } \\
\text { ox-LDL(h) }\end{array}$ & - & - & 48 & 48 & 24 & 36 & 48 & 48 \\
\hline $\mathrm{TC}(\mathrm{mg} / \mathrm{dl})$ & $145.5 \pm 13.1$ & $141.2 \pm 5.6$ & $265.9 \pm 14.5$ & $270.2 \pm 5.2$ & $269.1 \pm 8.7$ & $259.0 \pm 6.6$ & $271.4 \pm 8.4$ & $268.6 \pm 4.8$ \\
& & & & & & & & \\
$\mathrm{FC}(\mathrm{mg} / \mathrm{dl})$ & $93.4 \pm 3.2$ & $88.7 \pm 7.3$ & $94.1 \pm 7.9$ & $96.6 \pm 4.7$ & $91.9 \pm 6.4$ & $93.7 \pm 8.2$ & $95.3 \pm 6.2$ & $91.5 \pm 7.8$ \\
$\mathrm{CE}(\mathrm{mg} / \mathrm{dl})$ & $52.1 \pm 1.6$ & $53.7 \pm 7.1$ & $171.7 \pm 22.4$ & $175.8 \pm 3.7$ & $174.7 \pm 10.0$ & $168.2 \pm 13.4$ & $175.3 \pm 10.0$ & $169.2 \pm 17.9$ \\
\hline
\end{tabular}

presence of $1 \mu \mathrm{M}$ GABA or $20 \mu \mathrm{M}$ topiramate, lipid droplets in HMDMs exposed to $100 \mu \mathrm{g} /$ ml ox-LDL decreased significantly (Fig. 1 A-4 and B-4). The amount of ORO+ cells increased when HMDMs were exposed to $100 \mu \mathrm{g} / \mathrm{ml}$ ox-LDL (Fig. $1 \mathrm{D}-\mathrm{F}$ ), and the amount decreased significantly in the presence of $1 \mu \mathrm{M}$ GABA or $20 \mu \mathrm{M}$ topiramate (Fig. $1 \mathrm{D}$-E). However, in the presence of $10 \mathrm{nM}$ baclofen, the lipid droplets and the amount of ORO+ cells in HMDMs exposed to $100 \mu \mathrm{g} / \mathrm{ml}$ ox-LDL did not change (Fig. $1 \mathrm{C}-4$ and F).

TC, FC and CE in treated HMDMs were quantified using high performance liquid chromatography. There was a significant decrease in TC and CE in the presence of GABA or topiramate in HMDMs exposed to ox-LDL compared with HMDMs exposed to ox-LDL alone (Tables 2 and 3), and there was no change in the presence of baclofen (Table 4). There was a significant enhancement of apoA-I- and HDL $\left(\mathrm{HDL}_{2}\right.$ or $\left.\mathrm{HDL}_{3}\right)$-mediated [ $\left.{ }^{3} \mathrm{H}\right]$-cholesterol efflux in HMDMs exposed to ox-LDL in the presence of GABA or topiramate (Fig. 2 A-D). This enhancement was concentration and time dependent in the GABA-treated groups (Fig. $2 \mathrm{~A}$ and $\mathrm{C}$ ). Baclofen had no effect on apoA-I- and $\mathrm{HDL}\left(\mathrm{HDL}_{2}\right.$ or $\left.\mathrm{HDL}_{3}\right)$-mediated $\left[{ }^{3} \mathrm{H}\right]$-cholesterol efflux in HMDMs exposed to ox-LDL (Fig. 2 E-F). 


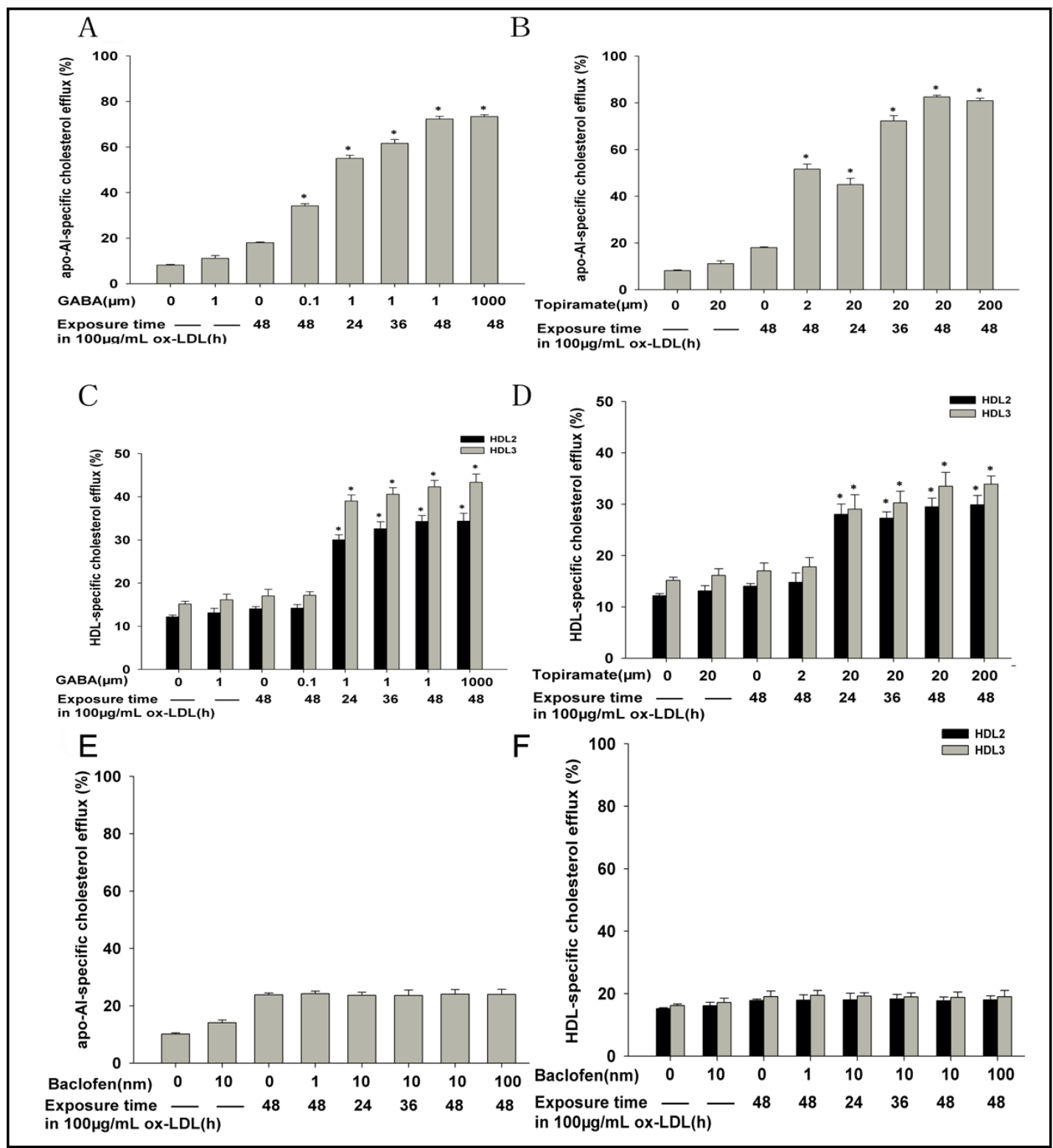

Fig. 2. Effects of GABAergic agents on apoA-I or HDL-mediated $\left[{ }^{3} \mathrm{H}\right]$-cholesterol efflux in HMDMs exposed to $100 \mu \mathrm{g} / \mathrm{ml}$ ox-LDL. (A and C) Percentage of cholesterol efflux from HMDMs exposed to $100 \mu \mathrm{g} / \mathrm{ml}$ ox-LDL in the absence or presence of GABA at varying concentrations of $0.1,1$ or $1000 \mu \mathrm{M}$. (B and D) Percentage of cholesterol efflux from HMDMs exposed to $100 \mu \mathrm{g} / \mathrm{ml}$ ox-LDL in the absence or presence of topiramate at varying concentrations of 2, 20 or $200 \mu \mathrm{M}$. (E and F) Percentage of cholesterol efflux from HMDMs exposed to $100 \mu \mathrm{g} / \mathrm{ml}$ ox-LDL in the absence or presence of baclofen at varying concentrations of 1,10 or $100 \mathrm{nM}$. In the presence of $1 \mu \mathrm{M}$ GABA, $20 \mu \mathrm{M}$ topiramate or $10 \mathrm{nM}$ baclofen, HMDMs were exposed to $100 \mu \mathrm{g} / \mathrm{ml} \mathrm{ox}$ LDL for 24, 36 or $48 \mathrm{~h}$, respectively. Medium and cell-associated apoA-I or HDL-mediated $\left[{ }^{3} \mathrm{H}\right]$-cholesterol was measured by liquid scintillation counting. ${ }^{*} P<0.05$ versus HMDMs exposed to $100 \mu \mathrm{g} / \mathrm{ml}$ ox-LDL alone.

GABA and topiramate down-regulate SR-A, CD36 and LOX-1 expression and up-regulate $A B C A 1, A B C G 1$ and $S R-B I$ expression in HMDMs exposed to ox-LDL

Using qRT-PCR and Western blotting, we assayed mRNA and protein levels of cholesterolmetabolism associated molecules in HMDMs exposed to ox-LDL in the absence or presence of GABA or topiramate, which include SR-A, CD36, LOX-1, ACAT1, ABCA1, ABCG1 and SR-BI.

Following incubation, mRNA expression levels of cholesterol-metabolism associated molecules were estimated by qRT-PCR. Figure 3 shows these results. Compared with mRNA 


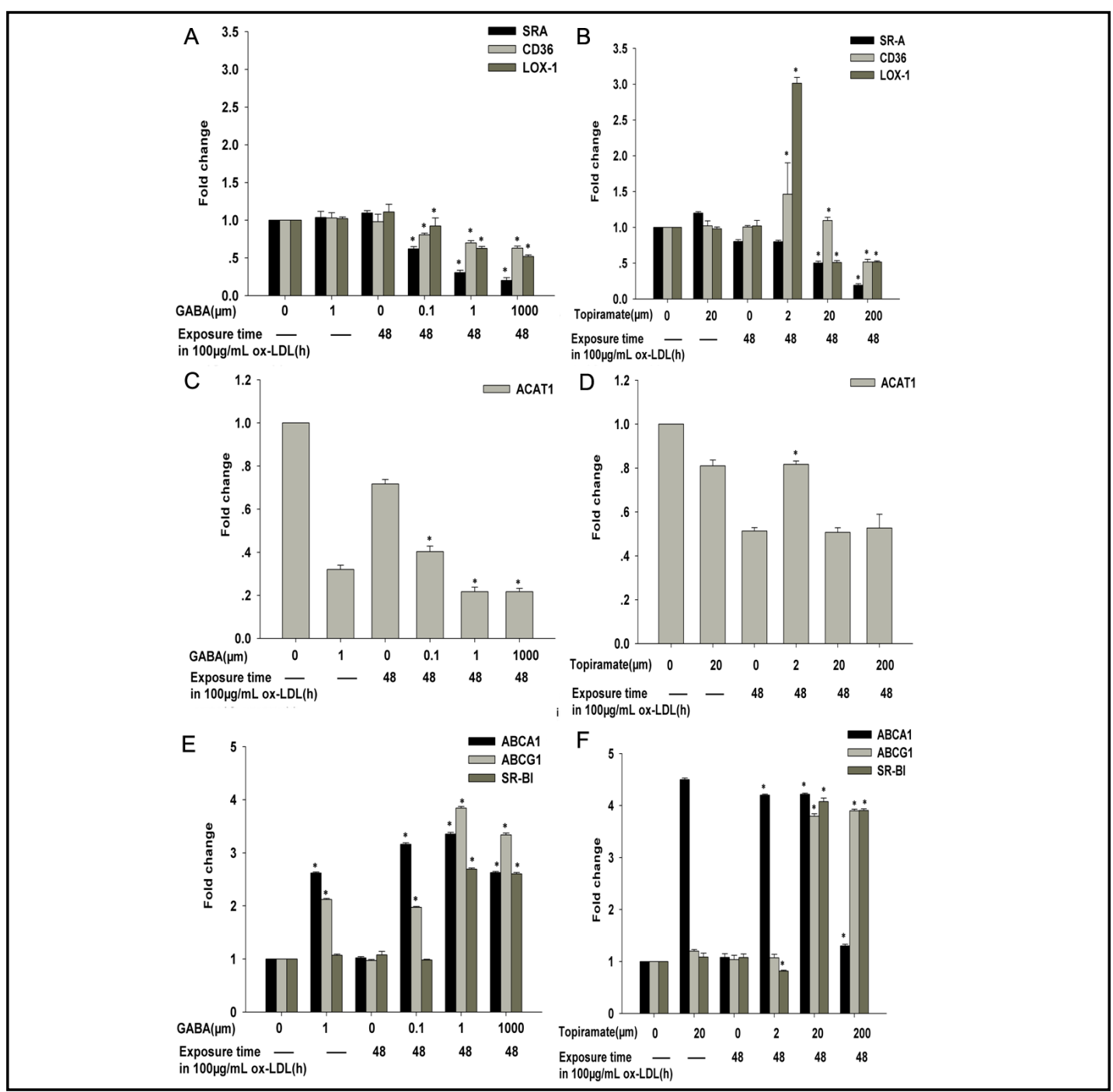

Fig. 3. Effects of GABA and topiramate on mRNA expression levels of SR-A, LOX-1, CD36, ACAT1, ABCA1, ABCG1 and SR-BI in HMDMs exposed to ox-LDL. (A, C and E) mRNA expression levels of SR-A, LOX-1, CD36, ACAT1, ABCA1, ABCG1 and SR-BI in HMDMs exposed to $100 \mu \mathrm{g} / \mathrm{ml}$ ox-LDL in the absence or presence of GABA at varying concentrations of $0.1,1$ or $1000 \mu \mathrm{M}(\mathrm{n}=3)$. (B, D and F) mRNA expression levels of SR-A, LOX-1, CD36, ACAT1, ABCA1, ABCG1 and SR-BI in HMDMs exposed to $100 \mu \mathrm{g} / \mathrm{ml}$ ox-LDL in the absence or presence of topiramate at varying concentrations of 2,20 or $200 \mu \mathrm{M}$ topiramate $(\mathrm{n}=3) \cdot{ }^{*} P<0.05$ versus HMDMs exposed to $100 \mu \mathrm{g} / \mathrm{ml}$ ox-LDL alone.

expression levels of SR-A/CD36/LOX-1 in HMDMs exposed to ox-LDL alone, mRNA expression levels of SR-A/CD36/LOX-1 in GABA-treated groups exposed to ox-LDL and SR-A/CD36 in topiramate-treated groups exposed to ox-LDL were down-regulated in a concentrationdependent manner. LOX-1 mRNA expression in topiramate-treated groups exposed to oxLDL decreased when the group was treated with $20 \mu \mathrm{M}$ or $200 \mu \mathrm{M}$ topiramate, but LOX-1 mRNA expression increased at $2 \mathrm{uM}$ topiramate (Fig. $3 \mathrm{~A}$ and B). ACAT1 mRNA expression was repressed in GABA-treated groups exposed to ox-LDL. However, there was no significant difference in ACAT1 expression levels between the $1 \mu \mathrm{M}$ GABA and $1000 \mu \mathrm{M}$ GABA treated groups (Fig. 3C). Additionally, $20 \mu \mathrm{M}$ topiramate and $200 \mu \mathrm{M}$ topiramate had no effect on ACAT1 mRNA expression in HMDMs exposed to ox-LDL. However, ACAT1 mRNA expression was elevated in the presence of $2 \mu \mathrm{M}$ topiramate (Fig. 3D). The mRNA expression levels of ABCA1, ABCG1 and SR-BI were up-regulated in HMDMs exposed to ox-LDL in the presence of GABA or topiramate (Fig. 3E and F). 


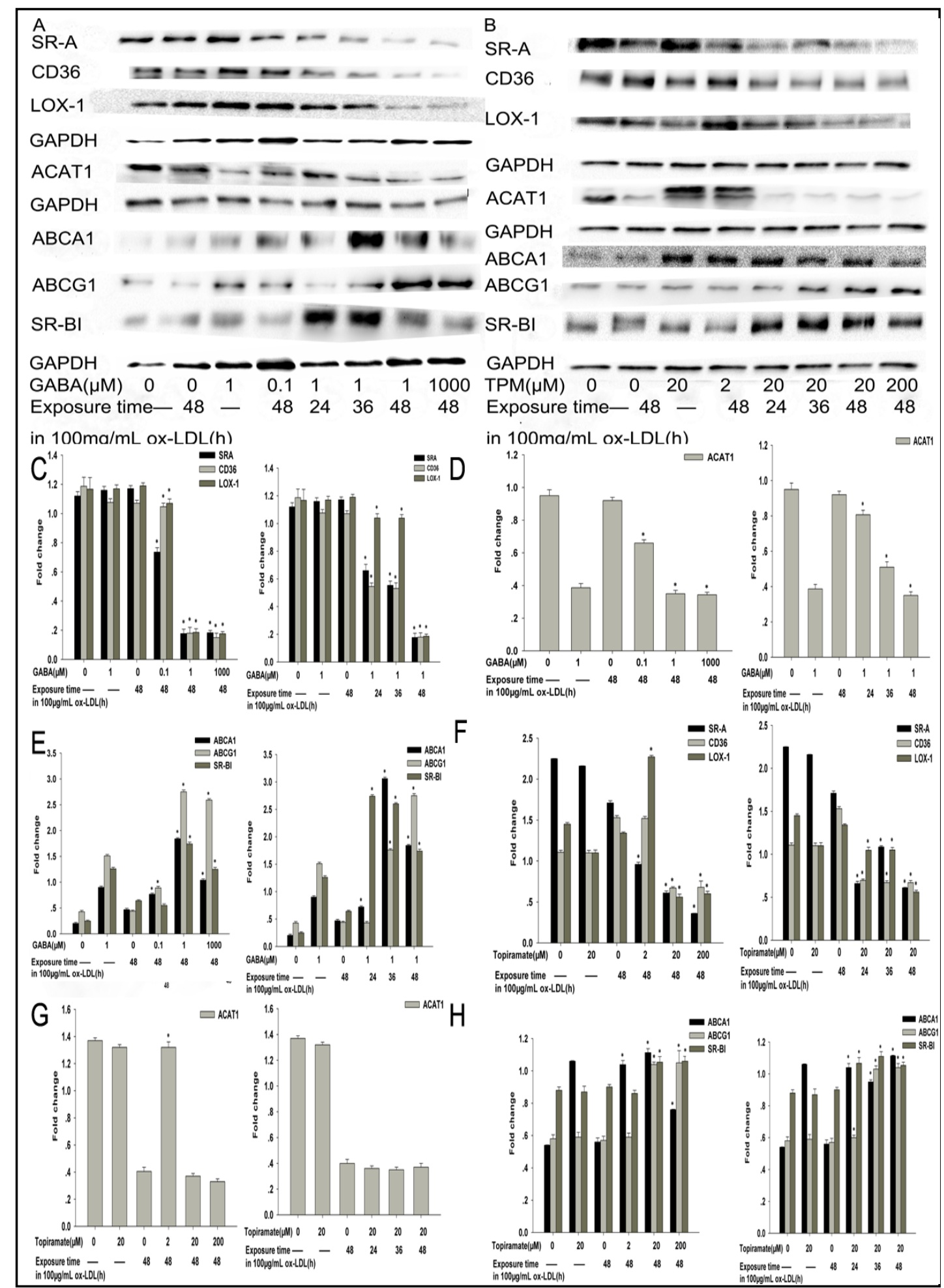

Fig. 4. GABA and topiramate modulate protein expression levels of SR-A, LOX-1, CD36, ACAT1, ABCA1, ABCG1 and SR-BI in HMDMs exposed to ox-LDL. (A and B) Protein expression levels of SR-A, LOX-1, CD36, ACAT1, ABCA1, ABCG1 and SR-BI in HMDMs exposed to $100 \mu \mathrm{g} / \mathrm{ml}$ ox-LDL in the absence or presence of GABA at varying concentrations of $0.1,1$ or $1000 \mu \mathrm{M}$ or topiramate at 2,20 or $200 \mu \mathrm{M}$. In the presence of 1 $\mu \mathrm{M}$ GABA or $20 \mu \mathrm{M}$ topiramate, HMDMs were exposed to $100 \mu \mathrm{g} / \mathrm{ml}$ ox-LDL for 24,36 or $48 \mathrm{~h}$. (C-H) Quantitative analyses of proteins in each group $(\mathrm{n}=3)$. ${ }^{*} P<0.05$ versus HMDMs exposed to $100 \mu \mathrm{g} / \mathrm{ml}$ ox-LDL alone. 


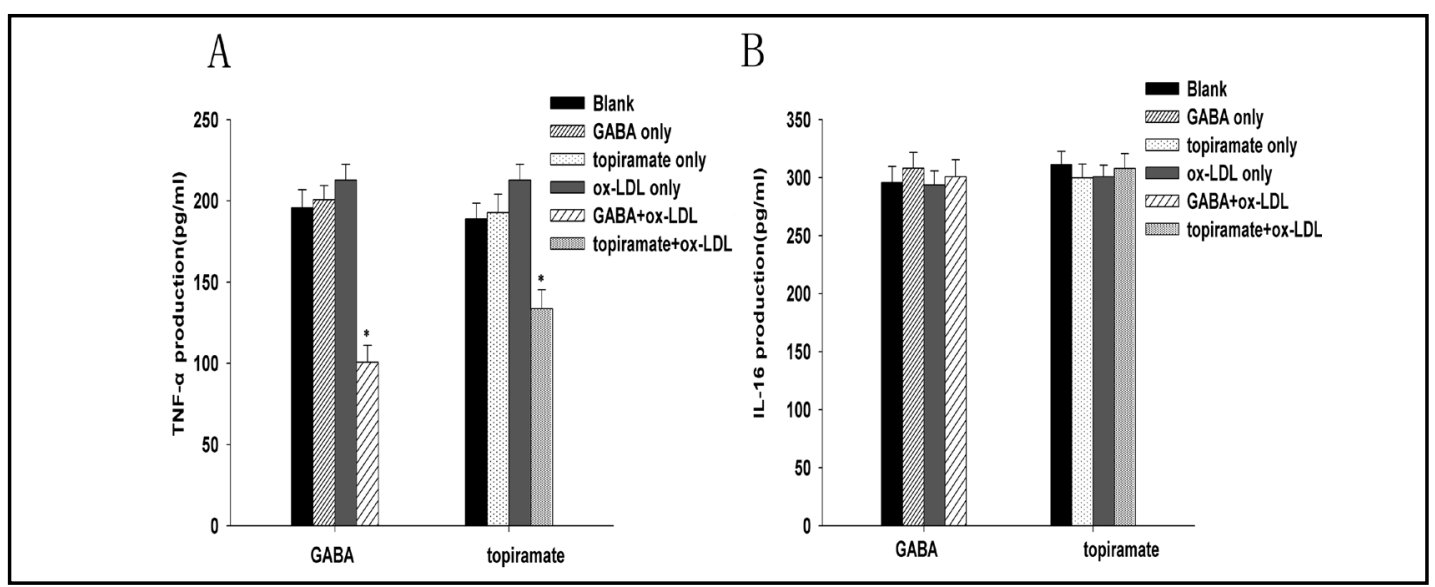

Fig. 5. GABA and topiramate modulate cytokine production. Cytokine production was measured in HMDMs (blank), HMDMs exposed to $100 \mu \mathrm{g} / \mathrm{ml}$ ox-LDL alone (ox-LDL only), HMDMs exposed to $1 \mu \mathrm{M}$ GABA or 20 $\mu \mathrm{M}$ topiramate (GABA only or topiramate only), HMDMs in the presence of $1 \mu \mathrm{M}$ GABA or $20 \mu \mathrm{M}$ topiramate exposed to $100 \mu \mathrm{g} / \mathrm{ml}$ ox-LDL (GABA+ox-LDL or topiramate+ox-LDL) (n=3). Data are shown as the mean \pm $\mathrm{SD}$ and are representative of the range of concentrations tested. ${ }^{*} P<0.05$ versus HMDMs exposed to 100 $\mu \mathrm{g} / \mathrm{ml}$ ox-LDL alone.

We further investigated protein expression levels of cholesterol-metabolism associated molecules. The changes were comparable in magnitude with mRNA expression levels of these molecules. Compared with protein expression levels of SR-A, CD36 and LOX-1 in HMDMs exposed to ox-LDL alone, the protein levels of SR-A, CD36 and LOX-1 in GABA-treated groups exposed to ox-LDL were repressed but not in a concentration- or time-dependent manner (Fig. $4 \mathrm{~A}$ and $\mathrm{C}$ ). In topiramate-treated groups exposed to ox-LDL, a similar reduction of protein expression levels of SR-A, CD36 and LOX-1 was observed. The protein expression of SR-A was concentration dependent (Fig. 4 B and F). GABA down-regulated the protein level of ACAT1 exposed to ox-LDL in concentration-dependent manner (Fig. $4 \mathrm{~A}$ and D). In line with ACAT1 mRNA level, ACAT1 protein level did not change in topiramate-treated groups exposed to ox-LDL (Fig. 4 B and G). The protein levels of ABCA1, ABCG1 and SRBI were significantly increased in HMDMs exposed to ox-LDL in the presence of GABA or topiramate compared with HMDMs exposed to ox-LDL alone, but not in a concentration- or time-dependent manner (Fig. 4 A, B, E and H).

We also found most cholesterol-metabolism associated molecules, such as SR-A, CD36, LOX-1, ACAT1, ABCA1 and ABCG1, increased or decreased their levels in HMDMs exposed to GABA or topiramate alone compared with HMDMs exposed to ox-LDL alone. The underlying cause is not clear.

GABA and topiramate modulate the production of inflammatory cytokines by HMDMS

Using ELISA, we tested the concentration of TNF- $\alpha$ and IL-6, the proinflammatory cytokines primarily produced by macrophages. The results confirmed that ox-LDL-induced TNF- $\alpha$ production was markedly decreased by GABA or topiramate treatment (Fig. 5 A). However, there was no significant change in the level of IL-6 in HMDMs exposed to ox-LDL in the presence of GABA or topiramate (Fig. 5 B).

GABA and topiramate modulate $p 38 M A P K$ phosphorylation and NF- $\kappa B$ activation

To more clearly define the mechanisms of GABAergic agents in HMDMs, two signaling pathways were explored following incubation with or without GABAergic agents. Compared with HMDMs exposed to ox-LDL alone, the phosphorylation expression of p38 mitogenactivated protein kinase (p38MAPK), which negatively regulates the expression of ABCA1 
Fig. 6. (A and $B$ ) Western blot for the phosphorylated p38MAPK protein was performed and compared with the nonphosphorylated form in HMDMs (blank), HMDMs exposed to $100 \mu \mathrm{g} /$ ml ox-LDL alone (ox-LDL only), HMDMs exposed to 1 $\mu \mathrm{M}$ GABA or $20 \mu \mathrm{M}$ topiramate (GABA only or topiramate only), HMDMs in the presence of 1 $\mu \mathrm{M}$ GABA or 20 $\mu \mathrm{M}$ topiramate exposed to 100 $\mu \mathrm{g} / \mathrm{ml} \quad$ ox-LDL (GABA+ox-LDL or top iramate +oxLDL) ( $n=3$ ). (C and

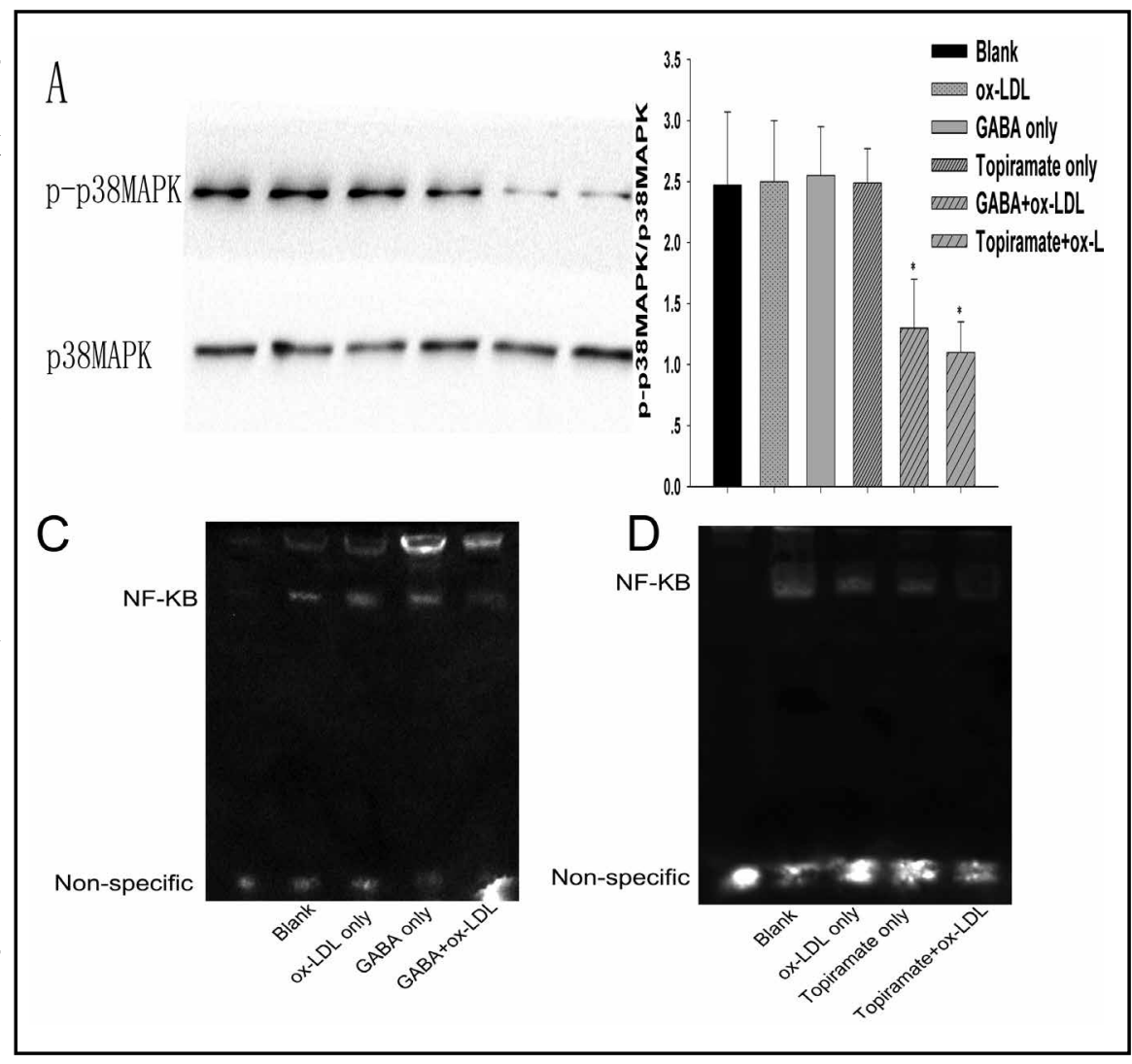

D) EMSA for the binding activity of NF- $\mathrm{KB}$ was examined in HMDMs (blank), HMDMs exposed to $100 \mu \mathrm{g} / \mathrm{ml}$ ox-LDL alone (ox-LDL only), HMDMs exposed to $1 \mu \mathrm{M}$ GABA or $20 \mu \mathrm{M}$ topiramate (GABA only or topiramate only), HMDMs in the presence of $1 \mu \mathrm{M} \mathrm{GABA}$ or $20 \mu \mathrm{M}$ topiramate exposed to $100 \mu \mathrm{g} / \mathrm{ml}$ ox-LDL (GABA+oxLDL or topiramate+ox-LDL) $(\mathrm{n}=3)$. Data are shown as the mean $\pm \mathrm{SD} .{ }^{*} P<0.05$ versus control group.

and $\mathrm{G} 1$, and the activation of NF- $\mathrm{B}$, which plays a central role in the inflammatory process, were markedly lower in GABA- and topiramate-treated groups, both exposed to ox-LDL (Fig. 6). These results suggested a possible involvement of p38MAPK and NF- $\kappa B$ signaling pathways in this response.

\section{Discussion}

In the light of previous reports of a GABAergic inhibitory effect on the phagocytic activity of immune cells, this study was designed to evaluate whether GABA and a GABA receptor agonist modulate the lipid ingestion of macrophage. We showed that administration of GABA and topiramate, a GABA-A receptor agonist, inhibited human macrophage-derived foam cell formation in vitro, while baclofen, a GABA-B receptor agonist, had no effect. The observed beneficial effects of GABA and topiramate were associated with restoration of the normal macrophage cholesterol metabolism, as evidenced by a reduced cholesterol content and enhanced cholesterol efflux in lipid-laden HMDMs.

Expression of GABA receptors has been demonstrated on human monocytes in vitro, indicating that GABA may directly affect macrophage activity [20]. The key finding of our study is that GABA and topiramate can modulate the expression of macrophage cholesterolmetabolism proteins. Our data indicated that the expression levels of SR-A, CD36, and LOX1 were markedly decreased, while ABCA1, ABCG1 and SR-BI were profoundly increased in 
GABA- and topiramate-treated lipid-laden HMDMs. These changes resulted in a decreasing cholesterol influx, attenuating free cholesterol esterification and increasing cholesterol efflux in lipid-laden HMDMs. Previous findings have demonstrated that the loss of SRA activity does not abrogate foam cell formation in hyperlipidemic mice due to alternative pathways, such as macropinocytosis and phagocytosis, for lipid uptake [21,22]. Deletion of ABCA1 or G1 alone could not accelerate the formation of lesions because of transporter mutual compensation and aqueous diffusion [23, 24]. The ACTIVATE clinical trial demonstrated that ACAT1 inhibition was ineffective and potentially harmful [6]. Those reports highlighted that the normal macrophage cholesterol metabolism involved the uptake, intracellular metabolism and efflux of cholesterol within the macrophage. The removal of one aspect of the circuit is compensated by another. It is likely that intervention on only one part of metabolic processes does not effectively prevent foam cell formation. In our study, GABAergic agents up- or down-regulated the expression of many macrophage cholesterol-metabolism proteins and had synergistic roles against macrophage foam cell formation. Therefore, GABAergic agents appear to be prospective foam cell targeting drugs that could ameliorate disrupted cholesterol mechanisms.

Macrophages are major producers of TNF- $\alpha$ and IL-6 [25]. Persistent overexpression of TNF- $\alpha$ has been measured in atherosclerotic plaque in response to both transient myocardial ischemia and reperfusion, which leads to adverse coronary outcomes [26]. IL-6 levels increase with acute ischemia and are a marker for plaque instability [27]. In our study, GABA and topiramate weakened the ox-LDL-induced TNF- $\alpha$ production in HMDMs in vitro and had no effect on IL-6 production. Some data have indicated that GABA decreases IL- 6 production in macrophages $[28,29]$. GABA-A receptor agonist decreased TNF- $\alpha$ production in a mouse model for allergic contact dermatitis [15] and diminished TNF- $\alpha$ and IL- 6 levels of purified antigen-presenting cells in C57Bl/6J mice of multiple sclerosis [9]. It was also reported that GABA increased mRNA expression levels of TNF- $\alpha$ and IL-6 in C57Bl/6J mice with multiple sclerosis and IL-6 production by macrophages in vitro [30]. These controversial results suggest that for GABAergic agents, there may be differences in underlying immune mechanisms in different autoimmune disease models.

We further demonstrated that GABA and topiramate attenuated the activation of p38MAPK and NF- $\kappa B$ in lipid-laden HMDMs. Previous studies showed that the phosphorylation of p38MAPK was markedly decreased in GABAergic agonist-treated macrophages [9]. Activation of the p38MAPK pathway can promote macrophage proliferation induced by oxidized low-density lipoprotein and suppress the expression of ABCA1/G1 and SR-BI [7, $31,32]$. For simultaneously regulating cholesterol-metabolism associated molecule gene expressions, the role of the TNF- $\alpha$ and NF- $\kappa B$ pathways was controversial. Marie et al. reported that TNF- $\alpha$ signals primarily through NF- $\kappa B$ induce ABCA1 expression in mouse peritoneal macrophages [33]. However, Jeffrey et al. indicated that an intact NF- $\kappa B$ pathway is necessary for TNF- $\alpha$ to have its full inhibitory effect on ABCA1 expression in a human intestinal cell line [34]. Lei et al. demonstrated that TNF- $\alpha$, through the NF- $\kappa B$ pathway, specifically enhances the expression of human ACAT1 gene to promote CE-laden cell formation from differentiating monocytes [31 ]. In the present study, we observed the inhibitory effects of GABA and topiramate on p38MAPK and NF- $\kappa B$ in lipid-laden HMDMs. Both pathways may be involved in the improvement of GABA and topiramate on macrophage cholesterol metabolism. Expression of GABA-A receptors has been demonstrated on human monocytes in vitro, indicating that GABA and topiramate may directly affect macrophage activity. However, because both drugs have a wide spectrum of targets, it is not clear whether there is a more global effect in terms of changes in macrophage gene or protein expression. The underlying mechanisms need to be explored.

In this study, we found that baclofen, a GABA-B receptor agonist, had no effect on the foam cell formation of HMDMs. The immunosuppressive action of baclofen may not have been involved in the lipid signaling pathway of macrophages.

In summary, our findings provide evidence for the first time that GABA and topiramate treatments inhibit the formation of human macrophage-derived foam cells. These findings 
suggest that there is a complex interplay between neurotransmitters and immune cells in atherosclerosis and that GABAergic agents may potentially be used as foam cell targeting drugs that could ameliorate disrupted cholesterol mechanisms.

\section{Acknowledgements}

This work was supported by the National Natural Science Foundation of China (grant No. 30700747/C08) and the Natural Science Foundation of Sichuan Province, China (grant No. 10ZC047).

\section{Conflicts of Interest}

None declared.

\section{References}

1 Moore KJ, Tabas I: Macrophages in the pathogenesis of atherosclerosis. Cell 2011;145:341-355.

2 Tiwari RL, Singh V, Barthwal MK: Macrophages: An elusive yet emerging therapeutic target of atherosclerosis. Med Res Rev 2008;28:483-544.

3 Kzhyshkowska J, Neyen C, Gordon S: Role of macrophage scavenger receptors in atherosclerosis. Immunobiology 2012;217:492-502.

4 Mitra S, Goyal T, Mehta JL: Oxidized ldl, lox-1 and atherosclerosis. Cardiovasc Drugs Ther 2011;25:419-429.

5 Fitzgerald ML, Mujawar Z, Tamehiro N: Abc transporters, atherosclerosis and inflammation. Atherosclerosis 2010;211:361-370.

6 Nissen SE, Tuzcu EM, Brewer HB, Sipahi I, Nicholls SJ, Ganz P, Schoenhagen P, Waters DD, Pepine CJ, Crowe TD, Davidson MH, Deanfield JE, Wisniewski LM, Hanyok JJ, Kassalow LM: Effect of acat inhibition on the progression of coronary atherosclerosis. N Engl J Med 2006;354:1253-1263.

7 Murao K, Yu X, Imachi H, Cao WM, Chen K, Matsumoto K, Nishiuchi T, Wong NC, Ishida T: Hyperglycemia suppresses hepatic scavenger receptor class b type i expression. Am J Physiol Endocrinol Metab 2008;294:E78-87.

8 Dionisio L, Jose De Rosa M, Bouzat C, Esandi Mdel C: An intrinsic gabaergic system in human lymphocytes. Neuropharmacology 2011;60:513-519.

-9 Bhat R, Axtell R, Mitra A, Miranda M, Lock C, Tsien RW, Steinman L: Inhibitory role for gaba in autoimmune inflammation. Proc Natl Acad Sci U S A 2010;107:2580-2585.

10 Jin Z, Mendu SK, Birnir B: Gaba is an effective immunomodulatory molecule. Amino Acids 2011;45:87-94.

11 Rane MJ, Gozal D, Butt W, Gozal E, Pierce WM, Jr., Guo SZ, Wu R, Goldbart AD, Thongboonkerd V, McLeish KR, Klein JB: Gamma-amino butyric acid type b receptors stimulate neutrophil chemotaxis during ischemia-reperfusion. J Immunol 2005; 174:7242-7249.

12 Demakova EV, Korobov VP, Lemkina LM: [determination of gamma-aminobutyric acid concentration and activity of glutamate decarboxylase in blood serum of patients with multiple sclerosis]. Klin Lab Diagn 2003:15-17.

13 Tian J, Dang HN, Yong J, Chui WS, Dizon MP, Yaw CK, Kaufman DL: Oral treatment with gammaaminobutyric acid improves glucose tolerance and insulin sensitivity by inhibiting inflammation in high fat diet-fed mice. PLoS One 2011;6:e25338.

14 Tian J, Yong J, Dang H, Kaufman DL: Oral gaba treatment downregulates inflammatory responses in a mouse model of rheumatoid arthritis. Autoimmunity 2011;44:465-470.

15 Duthey B, Hubner A, Diehl S, Boehncke S, Pfeffer J, Boehncke WH: Anti-inflammatory effects of the gaba(b) receptor agonist baclofen in allergic contact dermatitis. Exp Dermatol 2010;19:661-666.

16 Wang YF, Yang XF, Cheng B, Mei CL, Li QX, Xiao H, Zeng QT, Liao YH, Liu K: Protective effect of astragalus polysaccharides on atp binding cassette transporter a1 in thp-1 derived foam cells exposed to tumor necrosis factor-alpha. Phytother Res 2010;24:393-398.

-17 Wada Y, Sugiyama A, Yamamoto T, Naito M, Noguchi N, Yokoyama S, Tsujita M, Kawabe Y, Kobayashi M, Izumi A, Kohro T, Tanaka T, Taniguchi H, Koyama H, Hirano K, Yamashita S, Matsuzawa Y, Niki E, Hamakubo T, Kodama T: Lipid accumulation in smooth muscle cells under ldl loading is independent of ldl receptor pathway and enhanced by hypoxic conditions. Arterioscler Thromb Vasc Biol 2002;22:1712-1719. 
18 Zhou J, Ludlow LE, Hasang W, Rogerson SJ, Jaworowski A: Opsonization of malaria-infected erythrocytes activates the inflammasome and enhances inflammatory cytokine secretion by human macrophages. Malar J 2012;11:343.

19 Zhao Q Qian Y, Li R, Tan B, Han H, Liu M, Qian M, Du B: Norcantharidin facilitates lps-mediated immune responses by up-regulation of akt/nf-kappab signaling in macrophages. PLoS One 2012;7:e44956.

20 Alam S, Laughton DL, Walding A, Wolstenholme AJ: Human peripheral blood mononuclear cells express gabaa receptor subunits. Mol Immunol 2006;43:1432-1442.

21 Kuchibhotla S, Vanegas D, Kennedy DJ, Guy E, Nimako G, Morton RE, Febbraio M: Absence of cd36 protects against atherosclerosis in apoe knock-out mice with no additional protection provided by absence of scavenger receptor a i/ii. Cardiovasc Res 2008;78:185-196.

-22 Moore KJ, Kunjathoor VV, Koehn SL, Manning JJ, Tseng AA, Silver JM, McKee M, Freeman MW: Loss of receptor-mediated lipid uptake via scavenger receptor a or cd36 pathways does not ameliorate atherosclerosis in hyperlipidemic mice. J Clin Invest 2005;115:2192-2201.

23 Westerterp M, Murphy AJ, Wang M, Pagler TA, Vengrenyuk Y, Kappus MS, Gorman DJ, Nagareddy PR, Zhu X, Abramowicz S, Parks JS, Welch CL, Fisher EA, Wang N, Yvan-Charvet L, Tall AR: Deficiency of abca1 and abcg1 in macrophages increases inflammation and accelerates atherosclerosis in mice. Circ Res 2013

24 Yvan-Charvet L, Ranalletta M, Wang N, Han S, Terasaka N, Li R, Welch C, Tall AR: Combined deficiency of abca1 and abcg1 promotes foam cell accumulation and accelerates atherosclerosis in mice. J Clin Invest 2007;117:3900-3908.

25 Martinez FO, Sica A, Mantovani A, Locati M: Macrophage activation and polarization. Front Biosci 2008;13:453-461.

26 Ridker PM, Rifai N, Pfeffer M, Sacks F, Lepage S, Braunwald E: Elevation of tumor necrosis factor-alpha and increased risk of recurrent coronary events after myocardial infarction. Circulation 2000;101:2149-2153.

-27 Sarwar N, Butterworth AS, Freitag DF, Gregson J, Willeit P, Gorman DN, Gao P, Saleheen D, Rendon A, Nelson CP, Braund PS, Hall AS, Chasman DI, Tybjaerg-Hansen A, Chambers JC, Benjamin EJ, Franks PW, Clarke R, Wilde AA, Trip MD, Steri M, Witteman JC, Qi L, van der Schoot CE, de Faire U, Erdmann J, Stringham HM, Koenig W, Rader DJ, Melzer D, Reich D, Psaty BM, Kleber ME, Panagiotakos DB, Willeit J, Wennberg P, Woodward M, Adamovic S, Rimm EB, Meade TW, Gillum RF, Shaffer JA, Hofman A, Onat A, Sundstrom J, Wassertheil-Smoller S, Mellstrom D, Gallacher J, Cushman M, Tracy RP, Kauhanen J, Karlsson M, Salonen JT, Wilhelmsen L, Amouyel P, Cantin B, Best LG, Ben-Shlomo Y, Manson JE, Davey-Smith G, de Bakker PI, O'Donnell CJ, Wilson JF, Wilson AG, Assimes TL, Jansson JO, Ohlsson C, Tivesten A, Ljunggren O, Reilly MP, Hamsten A, Ingelsson E, Cambien F, Hung J, Thomas GN, Boehnke M, Schunkert H, Asselbergs FW, Kastelein JJ, Gudnason V, Salomaa V, Harris TB, Kooner JS, Allin KH, Nordestgaard BG, Hopewell JC, Goodall AH, Ridker PM, Holm H, Watkins H, Ouwehand WH, Samani NJ, Kaptoge S, Di Angelantonio E, Harari O, Danesh J: Interleukin- 6 receptor pathways in coronary heart disease: A collaborative meta-analysis of 82 studies. Lancet 2012;379:1205-1213.

-28 Tian J, Chau C, Hales TG, Kaufman DL: Gaba(a) receptors mediate inhibition of t cell responses. J Neuroimmunol 1999;96:21-28.

-29 Reyes-Garcia MG, Hernandez-Hernandez F, Hernandez-Tellez B, Garcia-Tamayo F: Gaba (a) receptor subunits rna expression in mice peritoneal macrophages modulate their il-6/il-12 production. J Neuroimmunol 2007;188:64-68.

30 Carmans S, Hendriks JJ, Slaets H, Thewissen K, Stinissen P, Rigo JM, Hellings N: Systemic treatment with the inhibitory neurotransmitter gamma-aminobutyric acid aggravates experimental autoimmune encephalomyelitis by affecting proinflammatory immune responses. J Neuroimmunol 2013;255:45-53.

-31 Senokuchi T, Matsumura T, Sakai M, Matsuo T, Yano M, Kiritoshi S, Sonoda K, Kukidome D, Nishikawa T, Araki E: Extracellular signal-regulated kinase and p38 mitogen-activated protein kinase mediate macrophage proliferation induced by oxidized low-density lipoprotein. Atherosclerosis 2004;176:233-245.

32 Yu X, Murao K, Imachi H, Li J, Nishiuchi T, Hosomi N, Masugata H, Zhang GX, Iwama H, Ishida T: Hyperglycemia suppresses abca1 expression in vascular smooth muscle cells. Horm Metab Res 2010;42:241-246.

-33 Gerbod-Giannone MC, Li Y, Holleboom A, Han S, Hsu LC, Tabas I, Tall AR: Tnfalpha induces abca1 through nf-kappab in macrophages and in phagocytes ingesting apoptotic cells. Proc Natl Acad Sci U S A 2006;103:3112-3117.

34 Field FJ, Watt K, Mathur SN: Tnf-alpha decreases abca1 expression and attenuates hdl cholesterol efflux in the human intestinal cell line caco-2. J Lipid Res 2010;51:1407-1415. 